\title{
Fabrication of high surface area graphene electrodes with high performance towards enzymatic oxygen reduction
}

\author{
Chiara Di Bari, ${ }^{\mathrm{a}, \dagger}$ Asier Goñi-Urtiaga,${ }^{\mathrm{b},{ }^{\dagger}}$ Marcos Pita, ${ }^{\mathrm{a}}$ Sergey Shleev, ${ }^{\mathrm{c}}$ Miguel D.
} Toscano, ${ }^{\mathrm{d}}$ Raquel Sainz, ${ }^{\mathrm{b}, *}$ and Antonio L. De Lacey ${ }^{\mathrm{a}, *}$

${ }^{a}$ Instituto de Catálisis y Petroleoquímica, CSIC, c/ Marie Curie 2, L10, 28049 Madrid, Spain.

${ }^{b}$ Nanoinnova Technologies SL, c/ Faraday 7, 28049 Madrid, Spain.

${ }^{c}$ Biomedical Sciences, Faculty of Health and Society, Malmo University, SE-0205 06 Malmo, Sweden.

${ }^{d}$ Protein Diversity, Novozymes A/S, Krogshojvej 36, 2880 Bagsvaerd, Denmark.

*E-mail: rsainz@nanoinnova.com; alopez@icp.csic.es

${ }^{\dagger}$ These authors contributed equally to the work

Electrochimica Acta 191 (2016) 500-509; http://dx.doi.org/10.1016/j.electacta.2016.01.101

\begin{abstract}
High surface area graphene electrodes were prepared by simultaneous electrodeposition and electroreduction of graphene oxide. The electrodeposition process was optimized in terms of $\mathrm{pH}$ and conductivity of the solution and the obtained graphene electrodes were characterized by Xray photoelectron spectroscopy, Fourier transform infrared spectroscopy, scanning electron microscopy and electrochemical methods (cyclic voltammetry and impedance spectroscopy). Electrodeposited electrodes were further functionalized to carry out covalent immobilization of two oxygen-reducing multicopper oxidases: laccase and bilirubin oxidase. The enzymatic electrodes were tested as direct electron transfer based biocathodes and catalytic currents as high as $1 \mathrm{~mA} / \mathrm{cm}^{2}$ were obtained. Finally, the mechanism of the enzymatic oxygen reduction reaction was studied for both enzymes calculating the Tafel slopes and transfer coefficients.
\end{abstract}


KEYWORDS: Graphene, Laccase, Bilirubin Oxidase, Oxygen Reduction Reaction, Biocathode.

\section{Introduction}

The fabrication of stable and reproducible electrodes is a key issue for the development of electrochemical devices and their implementation in our society. The scientific community has developed electroactive materials and electrode fabrication protocols aiming to tailor them for each electrochemical application. Devices such as fuel cells [1], supercapacitors [2] and batteries [3] need high surface area electrodes, high electrical conductivity and controllable porosity among other properties. High surface area carbonaceous materials, such as carbon nanotubes (CNT) $[4,5]$, carbon nanofibers (CNF) $[6,7]$ or graphene $[8,9]$, have attracted great interest due to their excellent electrical conductivity and mechanical properties. Graphene has been intensively studied in the latter years, focusing on its physicochemical and electrochemical properties to utilize it as a catalytic support on the electrode surface [10,11].

Graphene can be produced following many strategies: mechanical exfoliation of highly oriented pyrolytic graphite (HOPG), thermal decomposition of SiC wafers, chemical vapour deposition (CVD) on metal substrates, substrate-free CVD or reduction of graphene oxide (GO) by chemical, thermal or electrochemical means [12]. Each of these strategies provides graphene with different characteristics. Manufacturing graphene-based electrodes has to overcome the low reproducibility of the current fabrication methods, i.e. drop-casting, brushing or spraying [1315]. Recently, the electrodeposition of graphene oxide and its simultaneous electrochemical reduction on the electrode surface has been proposed as a reproducible method for the fabrication of stable and high surface area electrodes [16-18]. 
Graphene-based electrodes have been used for several applications, such as biosensing or as support for further immobilization of enzymes [9,10]. Multi-copper oxidases (MCOs) have been widely used in the preparation of biosensors and/or biocathodes due to their capability of catalyzing the oxidation of different organic and inorganic substrates with the concomitant reduction of oxygen to water directly to water without production of highly reactive oxygen species. MCOs typically contain four redox-active $\mathrm{Cu}$ ions classified according to their spectroscopic signal as T1 copper and the trinuclear cluster (TNC), which consists on a T2 copper ion and two T3 copper ions [19]. It is generally accepted that the T1 site is the primary electron acceptor from the substrate and then the electrons are transferred to the TNC cluster site which converts oxygen to water through a four electron reduction reaction. These enzymes attracted a great interest as they show fast direct electron transfer (DET) reactions [20].

In the present work the GO electrodeposition method has been optimized to produce a high surface area electrode that includes oxygen-based functional groups (-OH, -O-, $-\mathrm{C}=\mathrm{O},-\mathrm{COOH})$. Such functional groups allow the oriented immobilization of multi-copper oxidases (MCOs) to achieve DET (Figure 1). Myrothretium verrucaria bilirubin oxidase (BOx) and Trametes hirsuta laccase (Lac) have been selected as biocatalysts on the biocathodes, which could be used in enzymatic fuel cells [21]. However, this fabrication method of nanostructured electrodes can be extended to any electrochemical application where high surface area and high electrical conductivity are needed, and where oxygen functionalities can be used for the immobilization of different biogenic and non-biogenic catalysts.

\section{Materials and methods}

\subsection{Materials}


All chemicals used were analytical grade and were used as purchased. Graphene oxide (GO) from Nanoinnova Technologies SL (Spain) was used in powder form with no further purification. Nanoinnova's GO is produced by oxidation of graphite following Hummer's method [22].

4-nitrobenzene diazonium perchlorate, n-tetrabutyl ammonium fluoroborate, sodium nitrite,1(3-dimethylamino-propyl)-3-ethylcarbodiimide (ECD), morpholino-ethanesulphonic acid (MES), 2,2'-azinobis-(3-ethylbenzothiazoline-6-sulfonic acid) diammonium salt (ABTS), $\mathrm{NaClO}_{4}, \mathrm{D}_{2} \mathrm{O}$, 6-amino-2-naphtoic acid (NA), N-hydroxysuccinimide (NHS) and potassium ferrocyanide were purchased from Sigma-Aldrich (USA). Hydrochloric acid 37\%, acetic acid 96\%, KOH, $\mathrm{NaIO}_{4}$, sodium chloride, di-sodium hydrogen phosphate, sodium di-hydrogen phosphate and acetonitrile HPLC grade were purchased from Panreac (Spain). All aqueous solutions were prepared in deionized water using a Milli-Q system from Millipore (USA).

\subsection{Enzymes}

Lac from basidiomycete Trametes hirsuta from basidiomycete (strain T. hirsuta 56), was obtained from the laboratory collection of the Moscow State University of Engineering Ecology following the purification procedure previously reported [23]. Purified samples of Myrothecium verrucaria BOx, expressed recombinantly in Aspergillus oryzae, have been provided by Novozymes A/S (Denmark).

The specific activity of both enzymes was measured spectrophotometrically at $414 \mathrm{~nm}$ using 1 mM ABTS as substrate, using a Shimadzu UV-2401 PC spectrophotometer [24]. The measured values were 20 and $553 \mathrm{U}_{\mathrm{ABTS}} / \mathrm{mg}_{\text {enzyme }}$ for $\mathrm{BOx}$ and Lac respectively.

\subsection{Electrochemical measurements}


Electrochemical experiments were carried out in a standard three-electrode cell, with Pt wire as a counter electrode and a $\mathrm{Ag} / \mathrm{AgCl} / 3 \mathrm{M} \mathrm{KCl}$ reference electrode from Bioanalytical Systems (USA), using a $\mu$ Autolab Type II/FRA2 potentiostat/galvanostat from Metrohm Autolab B.V. (The Netherlands). All electrode potentials reported in this work are given vs. $\mathrm{Ag} / \mathrm{AgCl}, 3 \mathrm{M} \mathrm{KCl}$ (0.210 V vs. SHE) unless otherwise stated. Electrochemical impedance spectroscopy (EIS) experiments were recorded applying $10 \mathrm{mV}$ amplitude potential over a frequency range of 100 $\mathrm{kHz}$ to $0.1 \mathrm{~Hz} .10 \mathrm{mM} \mathrm{K}_{3}\left[\mathrm{Fe}(\mathrm{CN})_{6}\right]$ in $0.1 \mathrm{M} \mathrm{KCl}$ was used as an electrochemical probe. Impedance spectra were fitted using electrical equivalent circuits with ZView3.1c software from Scribner Associates Inc. (USA). All electrochemical measurements were performed using NOVA 1.9 software from Metrohm Autolab B.V.

Electrodeposition (ED) was performed on glassy carbon (GC) rotating disk electrodes of 5 $\mathrm{mm}$ diameter from Pine Instrument Co. (USA) and on gold-coated substrates $\left(1 \times 1 \mathrm{~cm}^{2}\right)$ from Metallhandler Schroer GmbH (Germany). The geometric area of the electrodes was considered for determining current densities. Prior to their use the electrodes were carefully cleaned as follows: GC electrodes were polished against $0.05 \mu \mathrm{m}$ alumina slurry (Buehler, USA) and then immersed into a 2:1 EtOH/ $\mathrm{H}_{2} \mathrm{O}$ solution and sonicated for $15 \mathrm{~min}$. The gold-coated substrates were cleaned using the previously reported procedure [25]. First of all an aqueous solution containing $150 \mathrm{mM} \mathrm{NaCl}$ and $0.5 \mathrm{mg} \mathrm{mL}^{-1} \mathrm{GO}$ was sonicated for $30 \mathrm{~min}$, and neutralized with $0.5 \mathrm{M} \mathrm{KOH}$. The exfoliated GO dispersion served as electrolyte for the ED of GO, which consisted on 30 cyclic voltammetry $(\mathrm{CV})$ scans ranging from 0.8 to $-1.5 \mathrm{~V}$ at $10 \mathrm{mV} / \mathrm{s}$ scan rate. The same process was used to modify both GC and gold electrodes. All electrodeposition experiments were carried out at room temperature, under deoxygenated conditions and with magnetic stirring. 
Electrocatalytic oxygen reduction experiments were carried out in $100 \mathrm{mM}$ phosphate buffer solution $\mathrm{pH} 7.4$ or $50 \mathrm{mM}$ acetate buffer $\mathrm{pH} 4.2$ with $100 \mathrm{mM} \mathrm{NaClO}_{4}$ at room temperature. Buffers were purged with $\mathrm{N}_{2}$ (99,999\% purity) from Air Liquide-Spain prior to experiments for deoxygenated conditions, and purged with $\mathrm{O}_{2}(99,999 \%$ purity, Air Liquide) in the case of ORR catalytic measurements. Mediated electron transfer (MET) measurements were carried out in presence of $0.1 \mathrm{mM}$ ABTS.

\subsection{Enzyme immobilization on graphene electrodes}

The electrochemically reduced graphene oxide-glassy carbon (erGO-GC) electrodes were functionalized with aryl diazonium derivatives to covalently immobilize the enzymes. For BOx immobilization the erGO-GC electrodes were functionalized with 2-carboxy-6-naphtoyl diazonium salt (NA-erGO-GC), which was synthesized in situ following a known procedure that furnishes naphtoic acid functionalized electrodes [26]. NA-erGO-GC electrodes were incubated in $20 \mu \mathrm{L}$ of $4 \mathrm{mg} \mathrm{mL}^{-1}$ BOx solution in $10 \mathrm{mM}$, pH 6.0 MES buffer for 1h, followed by the deposition of $10 \mu \mathrm{L}$ of the buffer solution containing $36 \mathrm{mM} \mathrm{EDC}$ and $17 \mathrm{mM}$ NHS on the electrode surface for $2 \mathrm{~h}$. For Lac immobilization the erGO-GC electrodes were functionalized with 4-aminoaryl diazonium salt (AP-erGO-GC) following a reported procedure that provides aminoaryl functionalized electrodes [27]. In parallel $5 \mu \mathrm{L}$ of $7.5 \mathrm{mg} / \mathrm{ml}$ Lac solution in $0.1 \mathrm{M}$,

pH 6.5 phosphate buffer were placed into $55 \mu \mathrm{L}$ of $10 \mathrm{mg} \mathrm{mL}^{-1} \mathrm{NaIO}_{4}$ solution for 30 minutes under daylight conditions. In order to increase the $\mathrm{pH}$ to about 7, $90 \mu \mathrm{L}$ of $100 \mathrm{mM} \mathrm{Na}_{2} \mathrm{HPO}_{4}$ were added to the solution. AP-erGO-GC electrodes were incubated in the treated Lac solution for 90 minutes. Finally, $10 \mu \mathrm{L}$ of $10 \mathrm{mM}$ MES buffer solution ( $\mathrm{pH}$ 6.0) containing $36 \mathrm{mM}$ EDC and $17 \mathrm{mM}$ NHS were deposited on the electrode surface for $2 \mathrm{~h}$.

\subsection{X-ray photoelectron spectroscopy characterisation}


X-ray photoelectron spectroscopy (XPS) measurements were performed using a PHOIBOS 150 9MCD analyser UHV system from PECS GmbH (Germany). Spectra with Mg (group 2) and $\mathrm{Al}$ (group 4) at $200 \mathrm{~W}$ and $12 \mathrm{kV}$ were recorded. Peak fitting and deconvolution was carried out using a CASAXPS 2.3.16Dev52 software with Shirley background, calibrating the spectra to $284.8 \mathrm{eV}$ peak of $\mathrm{C} 1 \mathrm{~s}$, and also using a Gaussian/Lorentzian fit of $\mathrm{G} / \mathrm{L}=30$.

\subsection{Scanning electron microscopy characterisation}

Scanning electron microscopopy (SEM) images were obtained using a TM-1000 Tabletop microscope from Hitachi (Japan).

\subsection{Fourier transform infrared spectroscopy characterisation}

Fourier transform infrared (FTIR) spectroscopy was performed in a Tensor 27 spectrometer from Bruker (Germany) equipped with a globar IR source, a MCT detector cooled by liquid $\mathrm{N}_{2}$, as well as a Whatman purge gas generator for removal of $\mathrm{CO}_{2}$ and $\mathrm{H}_{2} \mathrm{O}$. A FTIR spectroelectrochemical cell [28] was used to study the electrochemical reduction of a GO suspension $(0.5 \mathrm{mg} / \mathrm{mL})$ in $\mathrm{D}_{2} \mathrm{O} .1024$ scans with resolution of $2 \mathrm{~cm}^{-1}$ were recorded after applying a potential of $-1.5 \mathrm{~V}$ for 5, 30 and 60 minutes. Background subtraction and baselinecorrection of the FTIR spectra were done using OPUS software from Bruker.

\section{Results and discussion}

\subsection{Fabrication and characterisation of graphene electrodes}

The oxidation, and subsequent exfoliation, of graphite to graphene oxide (GO) by Hummer's method provides a material with high degree of oxygen functionalities (i.e. carboxyl, hydroxyl and epoxy groups), good dispersibility in aqueous solutions and negative zeta potential over almost the whole $\mathrm{pH}$ range (between -20 and $-40 \mathrm{mV}$ ) $[14,29,30]$. These properties allow the electrophoresis of GO sheets dispersed in an aqueous solution upon application of an electric 
field; therefore developing a method to simultaneously deposit and reduce GO by electrochemical means. Glassy carbon and gold substrates were modified with GO by its electrodeposition, providing high surface area and electrically conductive electrodes in the absence of binders or other additives.

The electrodeposited electrodes were fabricated by cyclic voltammetry, as shown in Figure 2A. The optimization of ED parameters was carried out by modifying the scan rate, number of cycles and electrolyte concentration. Successful ED was obtained by maintaining the scan rate between $10-50 \mathrm{mVs}^{-1}$, and applying a number of cycles between 10 and 40 to ensure an appropriate cover. In all experiments reported ED was performed at $10 \mathrm{mVs}^{-1}$ for 30 cycles. The salt concentration in solution ranged from 100 to $250 \mathrm{mM}$ to provide enough ionic strength and conductivity to the electrolyte solution [16]. These conditions allow the formation of a stable GO dispersion in terms of charge and size, also allowing optimum transfer of GO particles to the electrode and their subsequent electrochemical reduction. It could be noticed that increasing the number of scans lead to a direct enhancement of the capacitive area of the electrode. Cyclic voltammogramms (CVs) exhibited two well-defined anodic and two cathodic waves. The cathodic wave starting at $-1.0 \mathrm{~V}$ is attributed to the irreversible electrochemical reduction of GO [18], whereas the anodic and cathodic processes at -0.4 and -0.1 respectively may be attributed to electrochemically active oxygen functionalities present on the GO surface, as reported in literature [17]. The peak currents and capacitance increased with the number of scans, indicating that the deposition of GO and its concomitant reduction on the electrode surface indeed took place (Figure 2A).

Figure 2B shows the CVs of the erGO-GC electrodes before and after 30 min rotation at 1,500 rpm in the presence of $5 \mathrm{mM} \mathrm{K}_{3}\left[\mathrm{Fe}(\mathrm{CN})_{6}\right]$ in $0.1 \mathrm{M} \mathrm{KCl}$. The capacitive current, which is 
directly related to the surface area of the electrode, remained almost the same indicating that there is no material segregation. Therefore, the electroreduction process created a stable modified electrode due to the strong bonds between the electrode and the GO.

The erGO was characterized by SEM and XPS. For these measurements the electrodeposition of GO was done on Au-plated substrates (Figure S1, Supplementary Data). Gold is preferred as support for XPS measurements to avoid the interference of a carbon-based supporting material in the spectra. Furthermore, the Au plates fitted perfectly in the sample compartments of both SEM and XPS instruments, whereas the rotating GC electrodes did not. Figure 3 shows the morphology of a graphene-modified gold substrate obtained previously by cyclic voltammetry. In Figure 3A, a non-homogenous deposition is appreciated, suggesting that electrodeposition of GO followed a particle nucleation mechanism and subsequent growth of electroreduced GO aggregates. Aggregates with sizes as large as $200 \mu \mathrm{m}$ were generated in the electrodeposition method, creating $c a$. $100 \mu \mathrm{m}$ channels in between (Figure 3A). Additionally, pores of 10-20 $\mu \mathrm{m}$ diameters within the aggregates can be observed at higher magnification (Figure 3B). The high dispersion and porosity of graphene is expected to provide high surface area and good diffusion properties to the electrodes, which would enhance the overall performance in electrocatalytic applications in terms of catalyst coverage and mass transport, respectively.

During the electrodeposition process $\mathrm{GO}$ is reduced to graphene, referred here as electroreduced graphene oxide (erGO). Some oxygen functionalities are eliminated during this process, recovering the electrical conductivity (by $\mathrm{sp}^{2}$ configuration) of the graphene structure while partially maintaining oxygen functional groups. This is confirmed by XPS studies performed on GO and erGO (Figure 4). By this technique the oxygen-carbon ratio for both materials was calculated as 0.45 and 0.37 for GO and erGO, respectively. The analysis of the 
C1s binding energy region by deconvolution of the peak exhibited three different components in the case of GO (Figure 4A), which are assigned to aromatic sp ${ }^{2}$ structures at $284.3 \mathrm{eV}(40.77 \%)$, single C-O bonds (in hydroxyl and epoxy groups) at $286.3 \mathrm{eV}$ (48.54\%) and carbon doubly bonded to oxygen at $287.6 \mathrm{eV}(10.69 \%)$ [31]. In the O1s region (Figure 4B), deconvolution exhibited three different components, corresponding to doubly bonded oxygen (in carboxylic groups) at $530.6 \mathrm{eV}(4.10 \%)$, singly bonded oxygen (in hydroxyl, ether, epoxy and peroxy groups) at $532.4 \mathrm{eV}(95.38 \%)$ and singly bonded oxygen in peroxy acid and peroxy ester groups at $534.6 \mathrm{eV}(0.52 \%)$ [32].

Once the electrodeposition, and subsequent electroreduction of GO was achieved, the XPS spectrum differs notably due to the elimination of some oxygen functionalities during the process. In the case of $\mathrm{C} 1 \mathrm{~s}$ region of erGO (Figure $4 \mathrm{C}$ ), the component at $284.3 \mathrm{eV}$ exhibited an increase in the signal (47.05\%) and a new component at $285.2 \mathrm{eV}(3.86 \%)$ appeared corresponding to carbon-carbon double bonds $\left(\mathrm{C}=\mathrm{C}, \mathrm{sp}^{2}\right)$ and carbon-carbon single bonds $(\mathrm{C}-\mathrm{C}$, $\mathrm{sp}^{3}$ ), respectively. This confirms the restoration of the graphitic structure of graphene oxide after electrodeposition. Furthermore, the component at $286.3 \mathrm{eV}$ corresponding to oxygen-carbon single bonds, C-O, decreased (45.22\%) suggesting a loss in hydroxyl and/or ether/epoxy groups. The signal corresponding to double bonded $\mathrm{C}=\mathrm{O}$ groups at $287.6 \mathrm{eV}$ disappeared, indicating the elimination of carboxylic groups. A small contribution of a new component at $290.4 \mathrm{eV} \mathrm{(3.87 \% )}$ is attributed to $\pi \rightarrow \pi^{*}$ shake up satellite of graphitic carbons. ${ }^{33}$ The O1s region of erGO (Figure 4D) exhibited a decrease in the component at $532.4 \mathrm{eV}(86.9 \%)$, in good agreement with data obtained in the $\mathrm{C} 1 \mathrm{~s}$ binding region, corroborating partial loss of hydroxyl and/or epoxy/ether groups. The appearance of a new peak at $533.1 \mathrm{eV}(\% 13.1)$ attributed to singly bonded oxygen in 
acids, esters and hydroperoxides suggested the formation of these groups from the reduction of other oxygenated groups, i.e carboxylic acids.

In order to obtain further chemical information of the changes imposed on GO upon electrodeposition, FTIR spectro-electrochemical measurements were carried out for a GO suspension after applying a reductive potential $(-1.5 \mathrm{~V})$ for 5,30 and 60 minutes. As shown in Figure 5, the spectrum of GO before applying any reduction potential illustrates a broad and intense peak around 3500-3300 $\mathrm{cm}^{-1}$ attributed to $\mathrm{O}-\mathrm{H}$ stretching, a peak at $\sim 1720 \mathrm{~cm}^{-1}$ assigned to $\mathrm{C}=\mathrm{O}$ stretching of carboxyl and/or carbonyl groups, peaks corresponding to aromatic rings, $\mathrm{C}=\mathrm{C}$ and $\mathrm{C}-\mathrm{C}$ in the region between $1620-1450 \mathrm{~cm}^{-1}$, a peak around $1210 \mathrm{~cm}^{-1}$ attributed to aryl O-C stretching, and at around $1100 \mathrm{~cm}^{-1}$ a peak assigned to alkoxy or epoxy C-O stretching vibrations. The peaks immediately below $3000 \mathrm{~cm}^{-1}$ are generally ascribed to symmetric stretching vibrations for $-\mathrm{CH}_{2}$ groups [34-36]. Upon electrochemical reduction the relative intensity of the peaks attributed to oxygen functionalities, such as $\mathrm{O}-\mathrm{H}$ at $3500-3330$ and $\mathrm{C}=\mathrm{O}$ at $1720 \mathrm{~cm}^{-1}$, decrease significantly, as expected. Meanwhile the intensity of the bands typical of aromatic region in general has increased, suggesting the restoration of the aromatic $\mathrm{sp}^{2}$ carbon structure. Also the intensity of the peak at $1100 \mathrm{~cm}^{-1}$ increase, probably due to the formation of new C-O bonds from the reduction of carboxylic groups. From all this data it can be concluded that during the electrochemical reduction process the aromatic $\mathrm{sp}^{2}$ carbon structure is restored and although oxygen functionalities are indeed eliminated, some still remain in the material after the process, mainly as hydroxyl and epoxy groups.

Electrochemical characterization of the modified electrodes was carried out by impedance spectroscopy and cyclic voltammetry in presence of $\mathrm{K}_{3}\left[\mathrm{Fe}(\mathrm{CN})_{6}\right]$ as a redox probe. A satisfactory approximation $\left(\chi^{2}\right.$ about $10^{-3}$, where $\chi^{2}$ represents how accurate the fitting is respect 
to the experimental data) of EIS data (Figure 6A) was obtained using the fitting corresponding to the equivalent circuit (EC) reported in Figure 6B. These are in good agreement with the ECs reported in literature for similar systems [37]. In the circuit, $R_{s}$ is the cell resistance, $R_{c t}$ represents the charge transfer resistance at the solid-liquid interface and $Z_{\mathrm{w}}$ is the Warburg impedance resulting from the diffusion of the redox couple towards the electrode surface. $\mathrm{CPE}_{\mathrm{dl}}$ and $\mathrm{CPE}_{\mathrm{pol}}$ are constant phase elements modeling a non-ideal capacitor representing the charge separation of the double layer and the polarization of the erGO material, respectively. The CPE exponent $\alpha$ (Table 1) represents the roughness and non-uniformity of the electrode surface, with values ranging from 1 to 0.5 . CPEs were used to correctly fit the depressed semi-circle character of the response. The Warburg element is characterized by a diffusional time constant, a diffusional capacitance and a diffusional resistance. In the case of the erGO-GC electrode, without significant errors it was only possible to fit the spectra at the low frequency region with the addition of an extra capacitance in series with the Warburg element [38]. As seen in Figure 6A, the spectra exhibit a well-defined semicircle at the high frequency region with a larger diameter for bare GC, thus determining a $\mathrm{R}_{\mathrm{ct}}$ value two orders of magnitude greater than that of erGO-GC (Table 1). Capacitive lines appear in the low frequency region of the erGO-GC spectrum, typical behavior of a restricted diffusion within the graphene material $[38,39]$.

Table 1. Values of the parameters obtained by fitting the impedance spectra with the equivalent circuits shown in Figure 6B for bare GC and erGO-GC electrodes.

\begin{tabular}{|c|c|c|c|c|c|c|c|c|c|}
\hline & $\operatorname{Rs}(\Omega)$ & $\mathbf{R}_{\mathrm{ct}}\left(\mathbf{\Omega} \mathrm{cm}^{2}\right)$ & $\mathrm{CPE}_{\mathrm{dl}}\left(\mathrm{F} \mathrm{cm}^{-2} \mathrm{~s}^{\alpha-1}\right)$ & $\alpha_{\mathrm{dl}}$ & $Z_{w}\left(\Omega \mathrm{cm}^{-2} \mathbf{s}^{\alpha-1}\right)$ & $\tau$ & $\alpha$ & $\mathrm{CPE}_{\mathrm{pol}}\left(\mathrm{F} \mathrm{cm}^{-2} \mathrm{~s}^{\alpha-1}\right)$ & $\boldsymbol{\alpha}_{\mathrm{pol}}$ \\
\hline Bare GC & 69.6 & 151 & $2.84 \mathrm{E}-05$ & 0.88 & 19230 & 0.8 & 0.22 & - & - \\
\hline erGO-GC & 51.9 & 1.4 & 0.0018 & 0.75 & 2335 & 9 & 0.65 & 0.46 & 0.55 \\
\hline
\end{tabular}


The fact that erGO-GC exhibited smaller $\mathrm{R}_{\mathrm{ct}}$ and $\mathrm{Z}_{\mathrm{w}}$ values and higher $\mathrm{CPE}_{\mathrm{dl}}$ values compared to those of bare glassy carbon confirms improved electron transfer at the electrode-electrolyte interface, which is attributed to some extent to a more conductive character of the graphene material. The $\alpha_{\mathrm{dl}}$ value is lower in the case of erGO-GC, a sign of a higher porosity and nonuniformity of the graphene-electrode interface.

CVs of bare GC and erGO-GC electrodes were recorded in the presence of the electroactive redox probe $10 \mathrm{mM} \mathrm{K}_{3}\left[\mathrm{Fe}(\mathrm{CN})_{6}\right]$ in $0.1 \mathrm{M} \mathrm{KCl}$ at different scan rates (5 to $200 \mathrm{mV} \mathrm{s}^{-1}$ ). The effect of the scan rate on the redox couple signal for the electrodes is shown in Figure 7 . Well defined oxidation and reduction peaks are observed, as well as a significant increase in the capacitive area for the graphene-based electrode (Figure 7, A-B). The peak-to-peak separation $\left(\Delta \mathrm{E}_{\mathrm{p}}\right)$ is $65 \mathrm{mV}$ at $10 \mathrm{mVs}^{-1}$ for the erGO-GC electrode. As this value is related to the heterogeneous electron transfer rate constant, a low $\Delta \mathrm{E}_{\mathrm{p}}$ close to the ideal value of $59 \mathrm{mV}$ indicates a fast ET for a single-electron electrochemical reaction [10]. A slight peak potential shift with increasing scan rate was observed indicating a level of quasi-reversibility in the system. However, the linear relationship of peak intensity vs. the square root of the scan rate, following Randles-Sevcik relationship [40], indicates that the process is predominantly diffusion-controlled (Figure 7, C-D). This diffusion limitation is also suggested by a modest three-fold increase in the peak currents of the erGO-GC electrode compared to the bare GC one, despite the tenfold increase of the double layer capacitance of the modified electrode. This is in good agreement with the result obtained by impedance spectroscopy where the presence of the Warburg element confirms a diffusion-controlled behavior.

\subsection{Electrocatalytic performance of enzymatic electrodes}


The robust, stable and high surface area electrode of erGO-CG may be used as support for different electrochemical applications, such as the immobilization of enzymes and it was thus tested as a biosensor or a biocathode/bioanode. Indeed, the remaining oxygen functionalities of erGO provide reactive groups where further functionalization can be performed in order to carry out covalent immobilization of enzymes. In this work two redox enzymes from the multicopper oxidase family were used: $\mathrm{Lac}$ and $\mathrm{BOx}$. Both of them catalyze $\mathrm{O}_{2}$ reduction to $\mathrm{H}_{2} \mathrm{O}$ and have been frequently studied for biocathode development [41-43].

The surface of erGO was functionalized with an amino-aryl nanolayer in order to anchor Lac, which was done in two steps. First, Schiff's bases were formed between the amino groups of the electrode surface and aldehyde groups that had be obtained previously by oxidation of the laccase's sugar residues with periodate, and after by establishing amide bonds by carbodiimide coupling [27]. BOx was immobilized on naphtoic acid-functionalized electrodes by amide bonds between the lysine residues of the enzyme and the carboxylic groups of the electrode surface [26]. These methods provide robust and oriented immobilization of the enzymes on the electrode allowing fast DET $[26,27]$.

The electrocatalytic response to $\mathrm{O}_{2}$ reduction of the Lac-erGO-GC and BOx-erGO-GC electrodes was tested by cyclic voltammetry (Figure 8). The electrochemical results showed that in both cases the capacitive area of the electrode is enhanced in comparison with bare GC. Additionally a strong electrocatalytic effect is detected, reaching a current density plateau (after subtraction of the capacitive current) of ca. $1 \mathrm{~mA} / \mathrm{cm}^{2}$ and $0.4 \mathrm{~mA} / \mathrm{cm}^{2}$ for Lac and BOx modified electrodes, respectively, at $1500 \mathrm{rpm}$. All results are consistenly reproducible. $\mathrm{O}_{2}$ reduction control experiments were performed by immobilizing BOx on a GC electrode following the same strategies but in absence of erGO. In this case no catalytic response was observed (Figure 
S2, Supplementary Data).The same negative results have been previously obtained by our group also for Lac immobilized on GC electrode [44]. The absence of bioelectrocatalytic response is attributed to the lower electroactive area of bare GC compared to that of erGO-GC and to smaller pore dimensions, which do not facilitate an adequate immobilization of the enzymes for DET [44]. Therefore the presence of graphitic carbon is crucial for obtaining electroenzymatic reduction of $\mathrm{O}_{2}$ by DET. Figure 8 shows a clear mass transport limitation under stationary conditions due to the thickness of the catalytic layer; this limitation is reduced upon rotation of the erGO-GC electrode at $500 \mathrm{rpm}$. However, further increase in the rotational speed rate only marginally improved the response. Addition of $0.1 \mathrm{mM} \mathrm{ABTS}$ as redox mediator increased the current density by $20 \%$ and $24 \%$ for Lac-erGO-GC and BOx-erGO-GC electrodes respectively, indicating that some enzyme molecules are not adequately oriented for a DET reaction. The current density was measured at $100 \mathrm{mV}$ from the onset potential, where a purely kinetic regime is expected.

In order to study the purely kinetic contribution of the electrodes towards ORR [45], polarization curves of the Lac-erGO-GC and BOx-erGO-GC electrodes were obtained by subtracting the blank cathodic scans measured under $\mathrm{N}_{2}$ to the ones measured under $\mathrm{O}_{2}$, thus eliminating the capacitive currents of the electrodes (Figure 9A). Tafel plots were obtained from the polarization curves after correction of the ohmic drop caused by the resistances of the system (mainly by ionic resistance of the electrolyte) and of the mass transport limitations of oxygen from the solution to the electrode (Figure 9B) [45]. The iR drop was corrected using the $R_{s}$ value obtained from the intersection of the semicircle at the high frequency region of Nyquist plot, whereas the mass transport corrected current density was calculated using equation (1) [45], derived from the Koutecky-Levich equation for a first order reaction: 


$$
j_{k}=\frac{\left(j * j_{L}\right)}{\left(j_{L}-j\right)}
$$

where $j_{k}$ is the calculated kinetic current density and $j_{L}$ the limiting current density under mass transport control. The $j_{L}$ value at $500 \mathrm{rpm}$ rotation speed was theoretically calculated as 3.5 $\mathrm{mA} / \mathrm{cm}^{2}$ from the Levich equation (2) [40]:

$$
j_{L}=0.62 n F D_{0}^{2 / 3} v^{-1 / 6} C_{0} \omega^{1 / 2}
$$

where $n$ is the number of electrons involved in the ORR process (4), $F$ is the Faraday constant (96486 C/mol), $D_{0}$ is the diffusion constant of $\mathrm{O}_{2}\left(2.4 \times 10^{-5} \mathrm{~cm}^{2} / \mathrm{s}\right), v$ is the kinematic viscosity $\left(9.2 \times 10^{-3} \mathrm{~cm}^{2} / \mathrm{s}\right)$ and $C_{0}$ is the bulk concentration of $\mathrm{O}_{2}$ in a saturated water solution $\left(1.1 \times 10^{-6}\right.$ $\mathrm{mol} / \mathrm{cm}^{3}$ ) at the experimental conditions of $25^{\circ} \mathrm{C}, 705 \mathrm{mmHg}$ and $0.1 \mathrm{M}$ salt [46], and $\omega$ is the electrode rotation speed in $\mathrm{rad} / \mathrm{s}$.

From the polarization curves an onset potential of $0.64 \mathrm{~V}$ and $0.49 \mathrm{~V}$ was observed for LacerGO-GC and BOx-erGO-GC, respectively (Figure 9A). The ca. $150 \mathrm{mV}$ difference in onset potential is attributed to the difference in the redox potential of the copper T1 site of each enzyme [20], as the different proton activity of the electrolytes $(2.8 \mathrm{pH}$ units $)$ is not considered to have an effect due to the thermodynamic potential given by the Nernst relationship [47]. In order to propose an oxygen reduction reaction mechanism for the enzymatic electrodes, multistep and multi-electron reactions are considered with both an $\alpha$ transfer coefficient (a) and Tafel (b) expressions as follows [45]:

$$
\alpha=\left(\frac{\gamma}{v}+r \beta\right)\left(\text { a) } \quad \frac{d E}{\operatorname{dlog} i}=\frac{2.3 R T}{\alpha F}(\mathrm{~b})\right.
$$

where $\gamma$ stands for the number of electrons transferred in the step prior to the rate determining step, $v$ is the number of times the step occurs per cycle (stoichiometric number), $r$ is the number of electron transferred in the rate determining step, $\beta$ stands for the symmetry factor and $R$ is the ideal gas constant, $T$ the temperature and $F$ the Faraday constant. 
Tafel plots exhibited a linear region where slopes of $84 \mathrm{mV} \mathrm{dec}^{-1}$ and $129 \mathrm{mV} \mathrm{dec}^{-1}$ were obtained for BOx-erGO-GC and Lac-erGO-GC respectively (Figure 9B). This difference in Tafel slope, and thus transfer coefficient, suggests that despite both enzymes carried out the same electrochemical reaction, the reaction mechanism, or more likely, the rate determining step is different [48]. Solomon et al. proposed the following ORR mechanism for multicopper oxidases, where a ping-pong type mechanism is considered with four substrate molecules undergoing a single electron oxidation step at the $\mathrm{T} 1$ site for the four-electron reduction of oxygen to water at the TNC site [49]. Thorum et al. implemented this mechanism for Laccase-modified Au electrodes [45]:

$$
\begin{aligned}
& \text { 1. } \mathrm{Cu}_{T 1}^{2+}+e^{-} \rightarrow \mathrm{Cu}_{T 1}^{+} \\
& \text {2. } \mathrm{Cu}_{T 1}^{+}+\mathrm{Cu}_{T 2 / T 3}{ }^{2+} \rightarrow \mathrm{Cu}_{T 1}^{2+}+\mathrm{Cu}_{T 2 / T 3}{ }^{+} \\
& \text {3. } \mathrm{O}_{2}+\mathrm{Cu}_{T 3}^{+} \rightarrow \mathrm{PI} \\
& \text { 4. } \mathrm{PI} \rightarrow \mathrm{NI} \\
& \text { 5. } \mathrm{NI}+4 \mathrm{H}^{+} \rightarrow 2 \mathrm{H}_{2} \mathrm{O}+4 \mathrm{Cu}^{2+}
\end{aligned}
$$

where PI and NI are the peroxy and native intermediates, respectively [49]. Considering the expressions in equations $2 \mathrm{a}$ and $2 \mathrm{~b}$, the rate determining step for each process can be proposed [45]. In the case of Lac-erGO-GC electrode, an $\alpha$ transfer coefficient close to $1 / 2$ is obtained from the Tafel slope value of $129 \mathrm{mV} \mathrm{dec}^{-1}$, which is the expected value for an ideal one electron transfer process at ambient temperature [50]. If we consider the first step of the reaction mechanism as the rate limiting step, where $\alpha=\beta[45]$, a symmetry factor $(\beta)$ of 0.5 is obtained, which is the typical value considered in this kind of systems. Therefore, the Tafel plot suggests that DET to the T1 site of the immobilised Lac is the rate determining step of the overall bioelectrocatalysis, in good agreement with previous work by other authors on Lac electrodes 
$[45,50,51]$. However, in the case of our BOx-based electrode, $\alpha \sim 2 / 3$ is obtained from the Tafel slope value of $84 \mathrm{mV} \mathrm{dec}^{-1}$. Considering the same ORR mechanism for this electrode, $\alpha$ lays between the value for the first step being the rate limiting one $(\alpha=1 / 2)$ and the second step being rate limiting (where $\gamma=4, v=3$ and thus, $\alpha=4 / 3$ ). Therefore, this $\alpha$ value could be attributed to a mechanism where both first (outer electron transfer from the electrode) and second (intramolecular electron transfer) are rate-limiting [45]. On the one hand, these results are in excellent agreement with previously published data concerning possible changes of the rate limiting step during bioelectrocatalytic reduction of oxygen by $\mathrm{BOx}$ due to $\mathrm{pH}$ changes of the electrolyte, i.e., from heterogeneous to intramolecular ET in acidic and basic media, respectively $[41,52]$. On the other hand, we cannot rule out an effect of heterogeneous current density distribution due to the high surface area provided by graphene on the electrode surface [53].

\section{Conclusions}

Graphene has been used to enhance the properties of glassy carbon as electroactive platform for bioelectrocatalytic reduction of $\mathrm{O}_{2}$. The electrodeposition of graphene oxide on the glassy carbon supports results in a more uniform coverage than previously reported methods [13-15] with additional advantages, such as avoiding extra polymer layers. The electrochemical reduction of GO yielded a highly porous conductive surface that still has oxygen based functional groups (mainly hydroxyl or epoxy), which were used to immobilize two biocatalysts: Lac and BOx. In both cases high capacitive area and high current density (up to $1 \mathrm{~mA} \mathrm{~cm}$ ) were obtained. Mechanistic studies of BOx and Lac- based electrodes showed that they exhibit different Tafel slopes, suggesting a different rate limiting step during bioelectrocatalysis if the same ORR mechanism is considered. 
All these results highlight that this kind of electrodes could be used in the design of biocathodes or other electrochemical applications.

\section{Acknowledgements}

This work has received funding from the European Union's Seventh Framework Programme under grant agreement BIOENERGY, FP7-PEOPLE-2013-ITN-607793.

\section{References}

[1] N. Mahmood, C. Zhang, H. Yin, Y. Hou, Graphene-based nanocomposites for energy storage and conversion in lithium batteries, supercapacitors and fuel cells, J. Mater. Chem. A 2 (2014) 15-32.

(2) S.M. Chen, R. Ramachandran, V. Mani, R. Saraswathi, Recent Advancements in Electrode Materials for the High-Performance Electrochemical Supercapacitors: a Review. Int. J. Electrochem. Sci. 2014, 9, 4072-4085.

(3) Goriparti, S.; Miele, E.; De Angelis, F.; Di Fabrizio, E.; Proietti Zaccaria, R. P; Capiglia, C. Review on recent progress of nanostructured anode materials for li-ion batteries, J. Power Sources 257 (2014) 421-443.

(4) M.F.L. De Volder, S. H. Tawfick, R. H. Baughman, A. J. Hart, Carbon nanotubes: present and future commercial applications, Science 339 (2013), 535-539.

(5) C. de las Casas, W. Li, A review of application of carbon manotubes for lithium ion battery anode material, J. Power Sources 208 (2012) 74-85.

(6) L. Zhang, A. Aboagye, A.Kelkar, C. Lai, H. Fong, A review: carbon nanofibers from electrospun polyacrylonitrile and their applications, J. Mater. Sci. 49 (2014) 463-480. 
(7) L.F. Chen, X.D. Zhang, H.W. Liang, M. Kong, Q.F. Guan, P. Chen, Z.Y. Wu, S.H. Yu, Synthesis of nitrogen-doped porous carbon nanofibers as an efficient electrode material for supercapacitors, ACS Nano 6 (2012) 7092-7102.

(8) J. Filip, J. Tkac, Is graphene worth using in biofuel cells? Electrochim. Acta 136 (2014) $340-354$.

(9) C.N.R. Rao, A.K. Sood, K.S. Subrahmanyam, A. Govindaraj, Graphene: the new twodimensional nanomaterial, Angew. Chem. Int. Ed. 48 (2009) 7752-7777.

(10) Y. Shao, J. Wang, H. Wu, J. Liu, I.A. Aksay, Y. Lin, Graphene based electrochemical sensors and biosensors: a review. Electroanalysis 22 (2010) 1027-1036.

(11) I. V. Pavlidis, M. Patila, U.T. Bornscheuer, D. Gournis, H. Stamatis, Graphene-based nanobiocatalytic systems: recent advances and future prospects, Trends Biotechnol. 32 (2014) $312-320$.

(12) D.R. Dreyer, S. Park, C.W. Bielawski, R.S. Ruoff, The chemistry of graphene oxide, Chem. Soc. Rev. 39 (2010) 228-240.

(13) G. Eda, M. Chhowalla, Chemically derived graphene oxide: towards large-area thin-film electronics and optoelectronics, Adv. Mater. 22 (2010) 2392-2415.

(14) S. Kashyap, S. Mishra, S.K. Behera, Aqueous colloidal stability of graphene oxide and chemically converted graphene. J. Nanoparticles (2014), ID 640281.

(15) M, Pumera, A. Ambrosi, A. Bonanni, E.L.K. Chng, H.L. Poh, Graphene for electrochemical sensing and biosensing. Trends Anal. Chem., 29 (2010), 954-965.

(16) M. Hilder, B. Winther-Jensen, D. Li, M. Forsyth, D.R. MacFarlane, Direct electrodeposition of graphene from aqueous suspensions. Phys. Chem. Chem. Phys. 13 (2011) 91879193. 
(17) L. Chen, Y. Tang, K. Wang, C. Liu, S. Luo, Direct electrodeposition of reduced graphene oxide on glassy carbon electrode and its electrochemical application, Electrochem. Commun. 13 (2011) 133-137.

(18) Y. Jiang, Y. Lu, F. Li, T. Wu, L. Niu, W. Chen, Facile electrochemical codeposition of "clean" graphene-pd nanocomposite as an anode catalyst for formic acid electrooxidation. Electrochem. Commun. 19 (2012) 21-24.

(19) L. Quintanar, C. Stoj, A.B. Taylor, P.J. Hart, D.J. Kosman, E. I. Solomon, Shall we dance? How a multicopper oxidase chooses its electron transfer partner, Acc. Chem. Res. 40 (2007) 445-452.

(20) S. Shleev, J. Tkac, A. Christenson, T. Ruzgas, A.I. Yaropolov, J.W. Whittaker, L. Gorton, L. Direct electron transfer between copper-containing proteins and electrodes, Biosens. Bioelectron. 20 (2005) 2517-2554.

(21) M. Falk, M. Alcalde, P.N. Bartlett, A.L. De Lacey, L. Gorton, C. Gutierrez-Sanchez, R. Haddad, J. Kilburn, D. Leech, R. Ludwig, E. Magner, D.M. Mate, P.O. Conghaile, R. Ortiz, M. Pita, S. Pöller, T. Ruzgas, U. Salaj-Kosla, W. Schuhmann, F. Sebelius, M. Shao, L. Stoica, C. Sygmund, J. Tilly, M.D. Toscano, J. Vivekananthan, E. Wright, S. Shleev, Self-powered wireless carbohydrate/oxygen sensitive biodevice based on radio signal transmission, PLoS ONE 9 (2014) e109104.

(22) W.S. Hummers, R.E. Offeman, Preparation of graphitic oxide, J. Am. Chem. Soc. 80 (1958) 80, 1339-1339.

(23) S.V. Shleev, O.V. Morozova, O.V. Nikitina, E.S. Gorshina, T.V. Rusinova, V.A. Serezhenkov, D.S. Burbaev, I.G. Gazaryan, A.I. Yaropolov, Comparison of physico-chemical characteristics of four laccases from different basidiomycetes, Biochimie 86 (2004) 693-703. 
(24) R.E. Childs, W.G. Bardsley, The steady-state kinetics of peroxidase with 2,2'-azino-di(3-ethyl-benzthiazoline-6-sulphonic acid) as chromogen, Biochem. J. 145 (1975) 93-103.

(25) M. Pita, C. Gutierrez-Sanchez, D. Olea, M. Velez, C. Garcia-Diego, S. Shleev, V.M. Fernandez, A.L. De Lacey, High redox potential cathode based on laccase covalently attached to gold electrode, J. Phys. Chem. C 115 (2011) 13420-13428.

(26) C. Gutiérrez-Sánchez, M. Pita, M.D. Toscano, A.L. De Lacey, Bilirubin oxidase-based nanobiocathode working in serum-mimic buffer for implantable biofuel cell, Electroanalysis 25 (2013) 1359-1362.

(27) C. Gutierrez-Sanchez, M. Pita, C. Vaz-Dominguez, S. Shleev, A.L. De Lacey, Gold nanoparticles as electronic bridges for laccase-based biocathodes, J. Am. Chem. Soc. 134 (2012) $17212-17220$.

(28) D. Moss, E. Nabedryk, J. Breton, W. Mäntele, Redox-linked conformational changes in proteins detected by a combination of infrared spectroscopy and protein electrochemistry, Eur. J. Biochem. 187 (1990), 565-572.

(29) D. Chen, H. Feng, J. Li, Graphene oxide: preparation, functionalization, and electrochemical applications, Chem. Rev. 112 (2012) 6027-6053.

(30) Y. Si, E.T. Samulski, Synthesis of water soluble graphene, Nano Lett. 8 (2008) 16791682.

(31) F. Pogacean, C. Socaci, S. Pruneanu, A.R. Biris, M. Coros, L. Magerusan, G. Katona, R. Turcu, G. Borodi, Graphene based nanomaterials as chemical sensors for hydrogen peroxide a comparison study of their intrinsic peroxidase catalytic behavior, Sens. Actuators B: Chem. 213 (2015) 474-483. 
(32) P. Solís-Fernández, R. Rozada, J.I. Paredes, S. Villar-Rodil, M.J Fernández-Merino, L. Guardia, A. Martínez-Alonso, J.M.D. Tascón, chemical and microscopic analysis of graphene prepared by different reduction degrees of graphene oxide, J. Alloy. Compd. 536 (2012) S532S537.

(33) A.M. Bradshaw, S.L. Cerdabaum, W. Domcke, U. Krause, Plasmon coupling to core hole excitations in carbon, J. Phys. C: Solid State Phys. 7 (1974) 4503-4512.

(34) S.Y. Toh, K.S. Loh, S.K. Kamarudin, W.R.W Daud, Graphene production via electrochemical reduction of graphene oxide: synthesis and characterization, Chem. Eng. J. 251 (2014) 422-434.

(35) M. Acik, G. Lee, C. Mattevi, A. Pirkle, R.M. Wallace, M. Chhowalla, K. Cho, Y. Chabal, The role of oxygen during thermal reduction of graphene oxide studied by infrared absorption spectroscopy, J. Phys. Chem. C 115 (2011) 19761-19781.

(36) E. Pretsch, W. Simon, J. Seibl, T. Clerc, Tables of Spectral Data for Structure Determination of Organic Compounds, Springer-Verlag, Berlin, 1989.

(37) A. Navaee, A. Salimi, Graphene-supported pyrene-functionalized amino-carbon nanotube: a novel hybrid architecture of laccase immobilization as effective bioelectrocatalyst for oxygen reduction reaction, J. Mater. Chem. A 3 (2015) 7623-7630.

(38) K.P. Prathish, M.M. Barsan, D. Geng, X. Sun, C.M.A. Brett, Chemically modified graphene and nitrogen-doped graphene: electrochemical characterisation and sensing applications, Electrochim. Acta 114 (2013) 533-542.

(39) V. Pifferi, M.M. Barsan, M.E. Ghica, L. Falciola, C.M.A. Brett, Synthesis, characterization and influence of poly(brilliant green) on the performance of different electrode 
architectures based on carbon nanotubes and poly(3,4-ethylenedioxythiophene), Electrochim. Acta 98 (2013) 199-207.

(40) A. J. Bard, L.R. Faulkner, Electrochemical Methods: Fundamentals and Applications, John Wiley \& sons, New York, 1980.

(41) L. dos Santos, V. Climent, C.F. Blanford, F.A. Armstrong, mechanistic studies of the 'blue' cu enzyme, bilirubin oxidase, as a highly efficient electrocatalyst for the oxygen reduction reaction, Phys. Chem. Chem. Phys. 12 (2010) 13962-13974.

(42) A. Le Goff, M. Holzinger, S. Cosnier, recent progress in oxygen-reducing laccase biocathodes for enzymatic biofuel cells, Cell. Mol. Life Sci. 72 (2015) 941-952.

(43) N. Mano, L. Edembe, Bilirubin oxidases in bioelectrochemistry: features and recent findings, Biosens. Bioelectron. 50 (2013) 478-485.

(44) C.V. Dominguez, Inmovilizacion covalente y orientada de enzima lacasa para su uso como cátodo en pilas de combustible, Ph. D. Thesis, Universidad Autónoma de Madrid, 2009.

(45) M.S. Thorum, C.A. Anderson, J.J. Hatch, A.S. Campbell, N.M. Marshall, S.C. Zimmerman, Y. Lu, A.A. Gewirth, Direct electrocatalytic oxygen reduction by laccase on anthracene-2-methanethiol modified gold, J. Phys. Chem. Lett. 1 (2010) 2251-2254.

(46) D.R. Lide, Handbook of Chemistry and Physics, $87^{\text {th }}$ ed, Taylor \& Francis, Boca Raton, 2006.

(47) F. Xu, effects of redox potential and hydroxide inhibition on the ph activity profile of fungal laccases, J. Biol. Chem. 272 (1997) 924-928.

(48) G. Kear, F.C. Walsh, The characteristics of a true tafel slope, Corros. Mater. 6 (2005) 5155. 
(49) E.I. Solomon, R. Sarangi, J.S, Woertink, A.J. Augustine, J. Yoon, S. Ghosh, $\mathrm{O}_{2}$ and $\mathrm{N}_{2} \mathrm{O}$ activation by bi-, tri-, and tetranuclear cu clusters in biology, Acc. Chem. Res. 40 (2007) 40, $581-591$.

(50) P. Agbo, J.R. Heath, H.B. Gray, Catalysis of dioxygen reduction by Thermus thermophilus strain hb27 laccase on ketjen black electrodes, J. Phys. Chem. B 117 (2013) 527534.

(51) C.F. Blanford, C.E. Foster, R.S. Heath, F.A. Armstrong, Efficient electrocatalytic oxygen reduction by the 'blue' copper oxidase, laccase, directly attached to chemically modified carbons, Faraday Discuss. 140 (2008) 319-335.

(52) S. Shleev, V. Andoralov, M. Falk, C.T. Reimann, T. Ruzgas, M. Srnec, U. Ryde, L. Rulisek, On the possibility of uphill intramolecular electron transfer in multicopper oxidases: electrochemical and quantum chemical study of bilirubin oxidase, Electroanalysis 24 (2012) 1524-1540.

(53) J.S. Newman, C.W. Tobias, Theoretical analysis of current distribution in porous electrodes, J. Electrochem. Soc. 109 (1962) 1183-1191. 

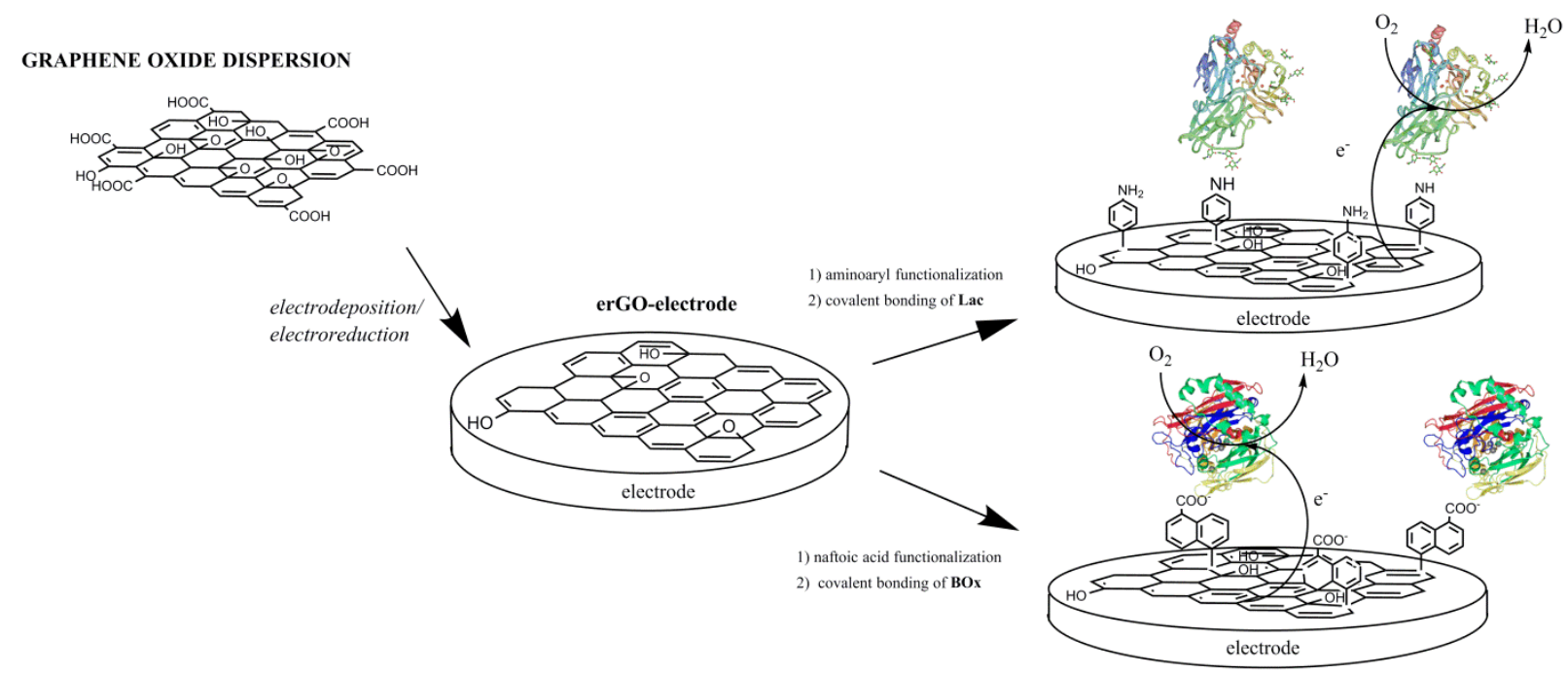

Figure 1. Scheme of graphene-based electrodes preparation and their modification with multicopper oxidases.
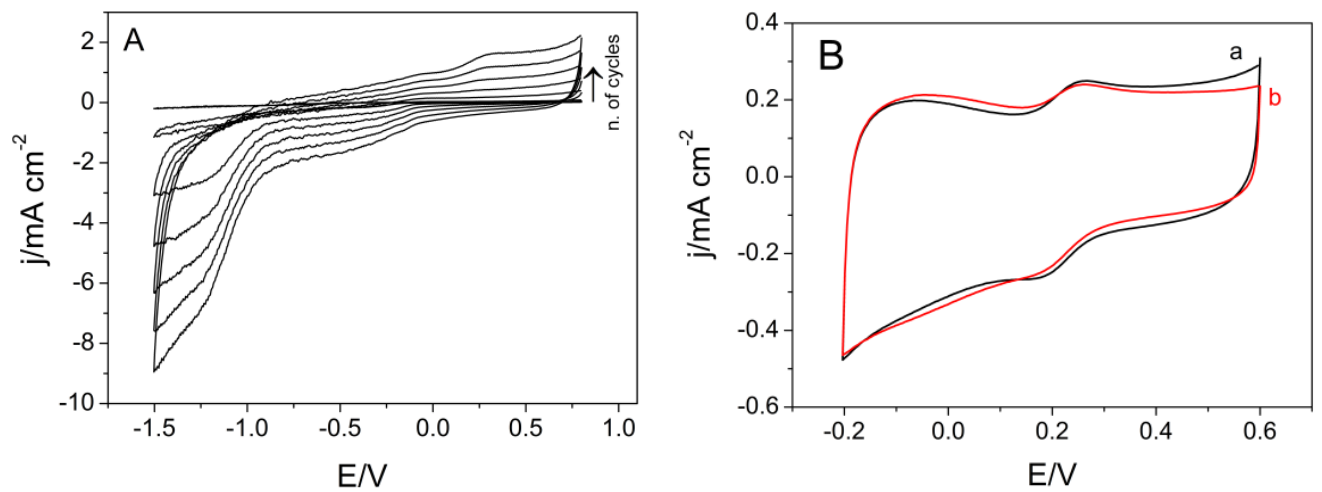

Figure 2. (A) Electrodeposition of GO on a GC electrode at $10 \mathrm{mV} \mathrm{s}^{-1} \mathrm{scan}$ rate $\left(1^{\mathrm{st}}, 5^{\text {th }}, 10^{\text {th }}\right.$, $15^{\text {th }}, 20^{\text {th }}, 25^{\text {th }}$ and $30^{\text {th }}$ scans are shown).(B) CVs of erGO-GC electrode at a scan rate of 50 $\mathrm{mVs}^{-1}$ in the presence of $5 \mathrm{mM}\left[\mathrm{Fe}(\mathrm{CN})_{6}\right]^{3+}$ before (a) and after (b) $30 \mathrm{~min}$ of rotation at 1,500 rpm. All CVs were done at room temperature. 

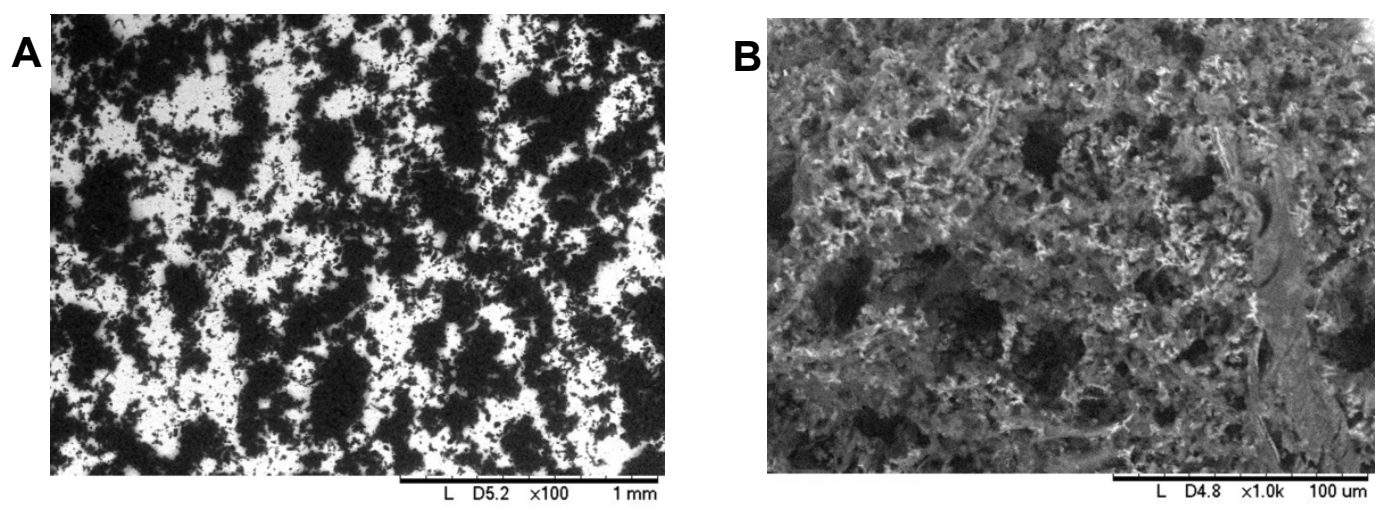

Figure 3. SEM micrographs at different magnifications, (A) x100 and (B) x1000 of electrodeposited GO by cyclic voltammetry (30 cycles) on a Au electrode.
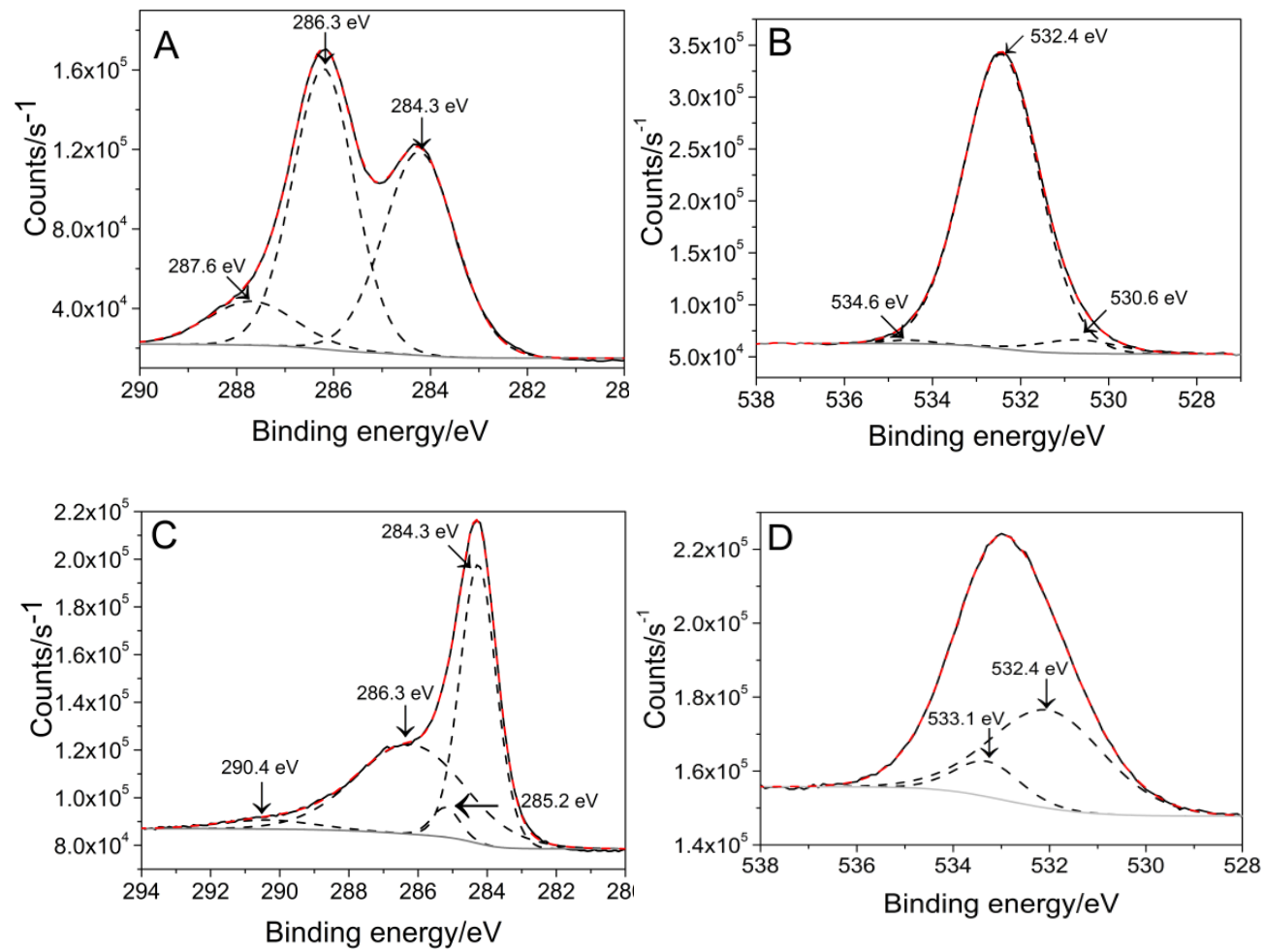

Figure 4. XPS spectra of $C 1 \mathrm{~s}(\mathrm{~A}, \mathrm{C})$ and $\mathrm{O} 1 \mathrm{~s}(\mathrm{~B}, \mathrm{D})$ bands of $(\mathrm{A}, \mathrm{B}) \mathrm{GO}$ and $(\mathrm{C}, \mathrm{D})$ er-GO. In all spectra the continuous black and grey lines are the experimental curve and the baseline correction, respectively; the hatched black lines are the different components obtained by the deconvolution process and the red ones are the total curves obtained from the sum of each component, exhibiting an optimum fit of the experimental data. The whole XPS spectra are shown in Figure S2. 


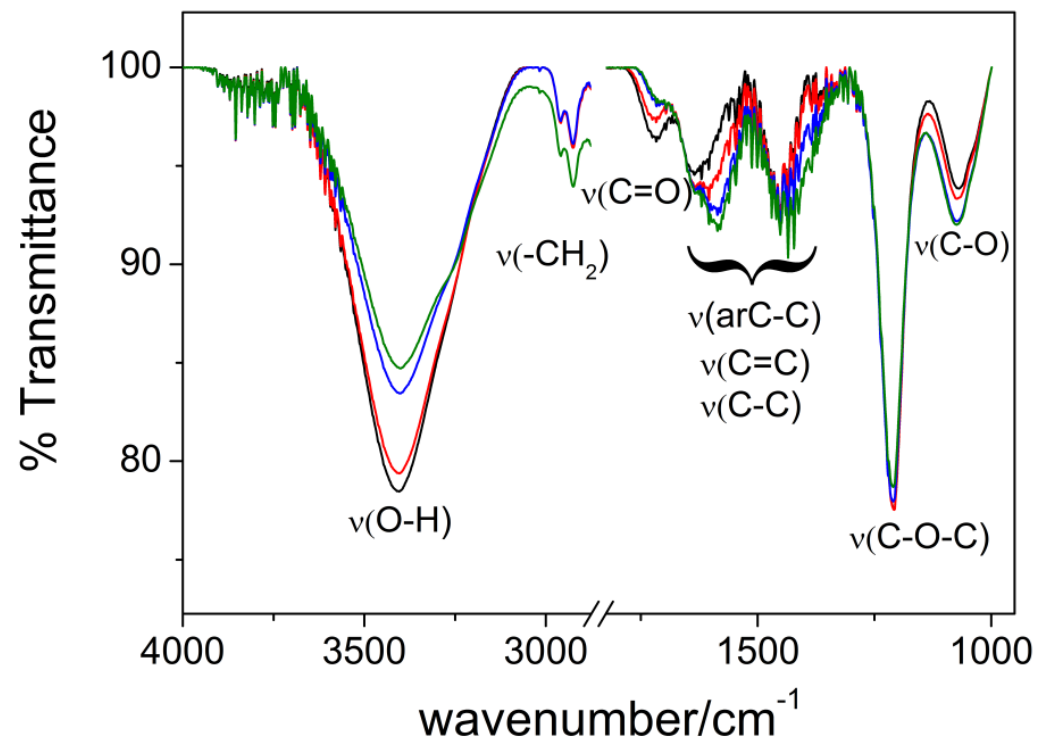

Figure 5. FTIR spectra of $\mathrm{GO}$ suspension in $\mathrm{D}_{2} \mathrm{O}$ before (black curve) and after applying a potential of $-1.5 \mathrm{~V}$ for 5 (red), 30 (blue) and 60 (green) minutes. Baseline correction and background subtraction $\left(\mathrm{D}_{2} \mathrm{O}\right)$ were made for all spectra.

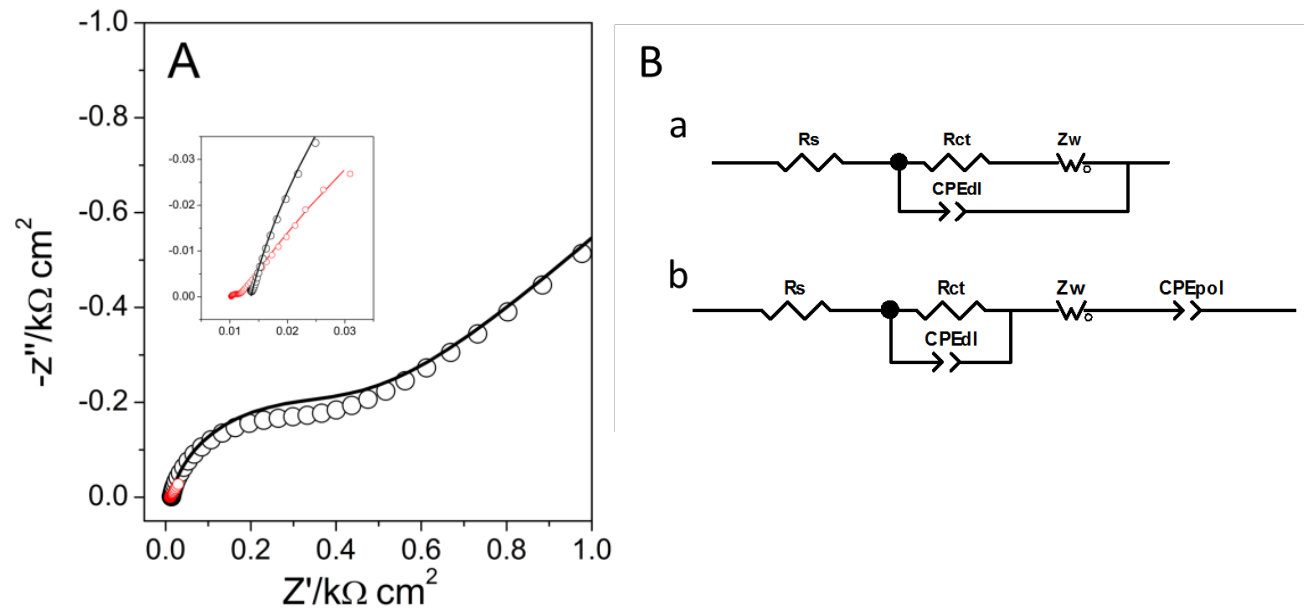

Figure 6. (A) EIS experimental spectra at room temperature for bare GC (black) and erGO-GC (red); the lines represent equivalent circuit fitting, whereas the dots represent the experimental data. Inset plot: magnification of the high frequency region of the complex plane plot. (B) Equivalent circuit of a) bare $\mathrm{GC}$ and b) erGO-GC electrode. 

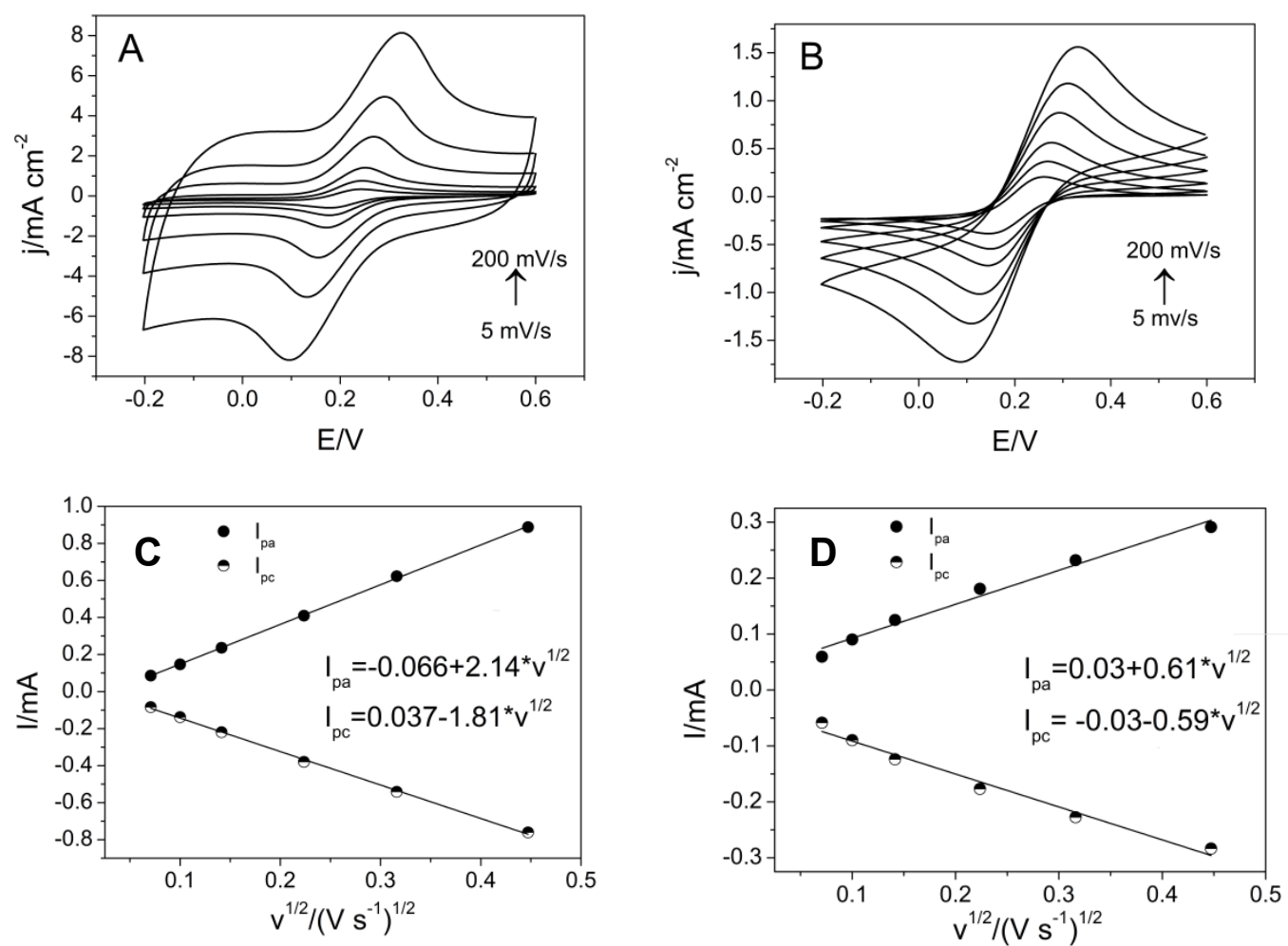

Figure 7. $\mathrm{CVs}$ recorded at room temperature in the presence of $10 \mathrm{mM} \mathrm{K}_{3}\left[\mathrm{Fe}(\mathrm{CN})_{6}\right]$ for erGOGC (A) and bare GC (B) electrodes at 5, 10, 20, 50, 100. $200 \mathrm{mVs}^{-1}$. Peak intensity vs. the square root of the scan rate for erGO-GC (C) and bare GC (D) electrodes. 

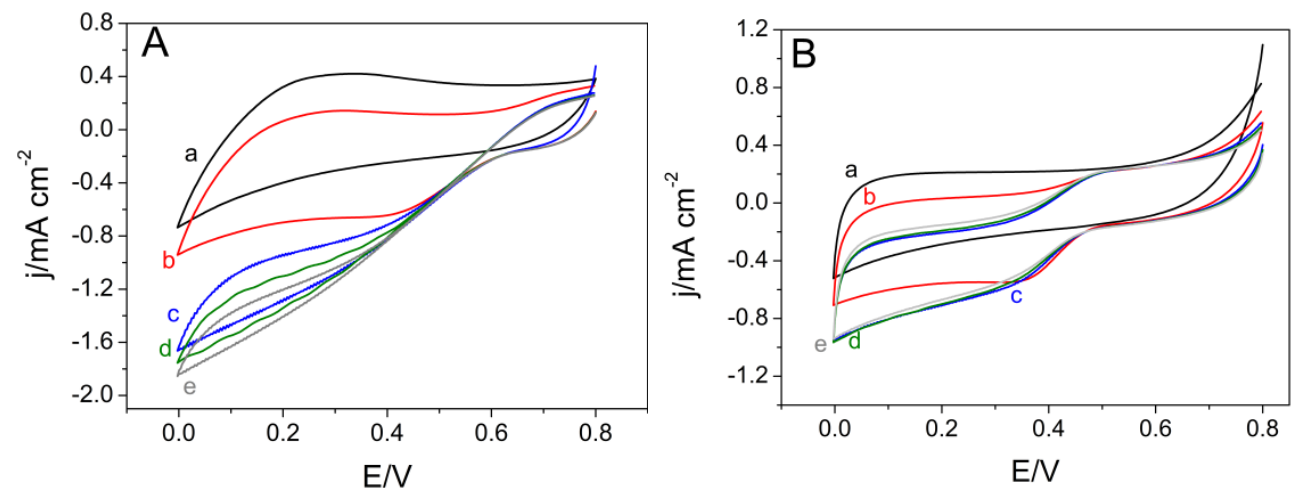

Figure 8. Electrocatalytic oxygen reduction at room temperature with (A) Lac-erGO-GC and (B) BOx-erGO-GC electrodes. Curves (a) and (b) represent CVs in a $\mathrm{N}_{2}$ (a) or $\mathrm{O}_{2}$ (b) saturated atmosphere at $0 \mathrm{rpm}$. Curves (c), (d) and (e) were recorded at 500, 1000 and $1500 \mathrm{rpm}$ respectively in an $\mathrm{O}_{2}$ saturated atmosphere. $\mathrm{CVs}$ were performed at $10 \mathrm{mVs}^{-1}$ in $50 \mathrm{mM}$ acetate buffer $\mathrm{pH} 4.2$ containing $100 \mathrm{mM} \mathrm{NaClO}$ (A) or $100 \mathrm{mM}$ phosphate buffer $\mathrm{pH} 7.4$ (B).
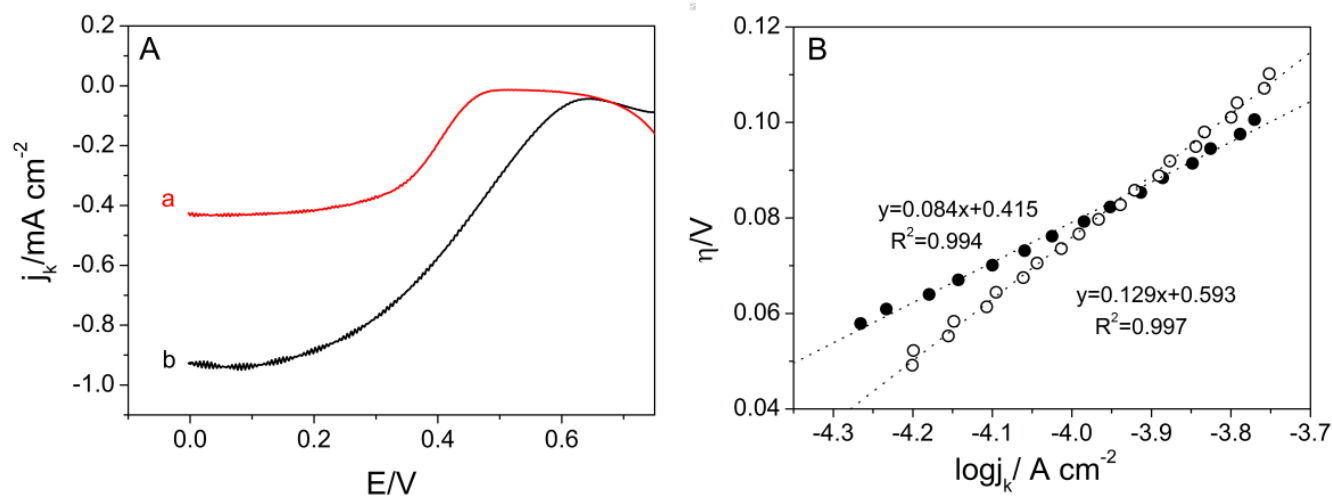

Figure 9. (A) Background-corrected polarisation curves for (a) BOx-erGO-GC and (b) LacerGO-GC electrodes at $500 \mathrm{rpm}$ rotation speed, room temperature and $10 \mathrm{mVs}^{-1}$ scan rate and (B) Tafel plots of Box-erGO-GC (black dots) and Lac-erGO-GC (white dots) electrodes obtained after correcting the ohmic drop and the mass transport limited current. 